\title{
A ATENÇÃO PRIMÁRIA À SAÚDE NO SUS: O PROCESSO DE CONSTRUÇÃO DE UMA POLÍTICA NACIONAL (1990-2006)
}

Carlos Henrique Assunção Paiva ${ }^{1}$

Recebido em: 24/04/2021

Aprovado em: 26/05/2021

Resumo: O artigo trata do contexto de instauração da Nova República, até 2006, quando é publicada a primeira Política Nacional de Atenção Básica do país. Em termos econômicos, políticos e sociais, o recorte temporal se caracteriza pelas expectativas e dificuldades de implantação da democracia e de políticas sociais capazes de enfrentar as condições sociais legadas pelo regime autoritário. Como parte dos esforços para se produzir respostas aos problemas médico-sanitários das populações, esse período vê emergir, sob uma renovada configuração institucional, ações e políticas no campo da Atenção Primária à Saúde. Em cerca de duas décadas, vemos consolidar tanto a formação de atores com identidade com a APS, como a formulação da primeira política nacional. Sem perder de vista estes marcos, a partir de entrevistas e fontes documentais, o texto identifica os caminhos que levaram a consolidação do SUS, resgatando o papel central da Reforma Sanitária Brasileira nesse processo; retrata o percurso de criação do Programa de Agentes Comunitários de Saúde e do Programa Saúde da Família. Por fim, informado pela construção de tais iniciativas, compreende a formulação da primeira Política Nacional de Atenção Básica (PNAB) com foco na identificação dos principais atores e mobilizações políticas necessárias para sua efetivação.

Palavras-Chave: Sistema Único de Saúde; Atenção Primária à Saúde; História da saúde pública; Política Nacional de Atenção Básica; Políticas de saúde

\section{ATENCIÓN PRIMARIA DE SALUD EN EL SUS: EL PROCESO DE CONSTRUCCIÓN DE UNA POLÍTICA NACIONAL (1990 - 2006)}

Resumen: El artículo aborda el contexto de la constitución de la Nueva República, hasta 2006, cuando se publica la primera Política Nacional de Atención Primaria del país. En términos económicos, políticos y sociales, el marco temporal se caracteriza por expectativas y dificultades en la implementación de políticas democráticas y sociales capaces de enfrentar las condiciones sociales legadas por el régimen autoritario. Como parte de los esfuerzos por producir respuestas a los problemas médicos y sanitarios de las poblaciones, este período ve el surgimiento, bajo una renovada configuración institucional, de acciones y políticas en el campo de la Atención Primaria de Salud. En cerca de dos décadas, vemos consolidarse tanto la

\footnotetext{
${ }^{1}$ Professor do Programa de Pós-Graduação em História das Ciências e da Saúde (Fiocruz) e do Programa de PósGraduação em Saúde da Família (PPGSF/UNESA). Doutor em Saúde Coletiva (IMS/UERJ). E-mail: carlos.paiva@fiocruz.br. Orcid: https://orcid.org/0000-0002-7478-9628.
} 
formación de actores con identidad con la APS, como la formulación de la primera política nacional. El texto identifica los caminos que llevaron a la consolidación del SUS, rescatando el papel central de la Reforma Sanitaria brasileña en este proceso; retrata el camino de creación del Programa de Agentes de Comunitários de Saúde y el Programa de Saúde da Família. Finalmente, informado por la construcción de dichas iniciativas, comprende la formulación de la primera Política Nacional de Atención Primaria (PNAB) con un enfoque en la identificación de los principales actores y movilizaciones políticas necesarias para su implementación.

Palabras clave: Sistema Único de Salud; Atencion Primaria de la Salud; Historia de la salud pública; Política Nacional de Atención Primaria; Políticas de salud

\title{
PRIMARY HEALTH CARE IN SUS: THE PROCESS OF BUILDING A NATIONAL POLICY (1990 - 2006)
}

\begin{abstract}
The article deals with the context of the establishment of the Nova República, until 2006, when the country's first National Primary Care Policy is published. In economic, political and social terms, the time frame is characterized by expectations and difficulties in implementing democracy and social policies capable of facing the social conditions bequeathed by the authoritarian regime. As part of the efforts to produce responses to the medical and sanitary problems of the populations, this period sees the emergence, under a renewed institutional configuration, of actions and policies in the field of Primary Health Care. In about two decades, we see consolidating both the formation of actors with identity with PHC, such as the formulation of the first national policy. The text identifies the paths that led to the consolidation of SUS, rescuing the central role of the Brazilian Sanitary Reform in this process; portrays the path of creation of the Programa de Agentes Comunitários de Saúde and the Programa de Saúde da Família. Finally, informed by the construction of such initiatives, it comprises the formulation of the first National Primary Care Policy (PNAB) with a focus on identifying the main actors and political mobilizations necessary for its implementation.
\end{abstract}

Keywords: Unified Health System; Primary Health Care; History of public health; National Primary Care Policy; Health policies

\section{Introdução:}

A articulação de pessoas e instituições com vistas ao restabelecimento da democracia e a efetivação do direito à saúde; a expectativa de implantação do que seria a primeira política nacional para a Atenção Primária, com o Programa Nacional de Serviços Básicos de Saúde (Prevsaúde); por fim, os esforços, em boa parte bem-sucedidos, para a implantação de um renovado sistema de saúde dão a medida das imensas expectativas de mudanças, capazes de mobilizar os mais diversos atores sociais no correr da década de 1980. Na década seguinte, com a publicação das chamadas Leis Orgânicas da Saúde (8.080/90 e 8.142/90), os desafios se abriram para uma agenda que fosse capaz de dar conta da implantação concreta de boa parte das expectativas construídas até então. 
Questões que buscavam refletir sobre quais seriam as estratégias para converter o direito à saúde em serviços, políticas e programas concretos para a população, permeavam os debates do setor da saúde. Nesse sentido, é possível identificar desafios, relativos à necessária programação e planejamento de ações no período inicial de vigência do Sistema Único de Saúde (SUS). Atente-se que, na contramão das expectativas, a primeira década de funcionamento do novo sistema coincide com uma fase marcada pelos chamados "ajustes estruturais" na economia, cujo foco foi a diminuição do papel do Estado e o incentivo ao mercado como estruturante do capital e supostamente como principal ofertador de bens e serviços. Tal impacto do ajuste no processo de construção do SUS é bastante referido pela literatura e conhecido entre os estudiosos de políticas públicas (Faleiros et al, 2005)

O presente artigo se debruça sobre esse conturbado período, até o ano de 2006, quando é publicada aquela que é reconhecida formalmente como a primeira Política Nacional de Atenção Básica (PNAB) do país. Em termos econômicos, políticos e também sociais, o recorte temporal se caracteriza pelas expectativas e dificuldades até aqui sumarizadas. Como parte dos esforços para se produzir especificamente respostas aos problemas médico-sanitários das populações, esse mesmo período vê emergir, sob uma renovada configuração institucional, ações e políticas no campo da Atenção Primária à Saúde (APS). Em um contexto temporal de cerca de duas décadas, vemos consolidar tanto a formação de atores com identidade com a APS, como, especialmente, a formulação daquela que seria sua primeira política de alcance nacional implantada.

O contexto é também palco dos debates entre aqueles que defendiam uma APS abrangente versus APS seletiva ${ }^{2}$. A rigor, sob nosso recorte de análise, os diferentes governos brasileiros foram pautados por uma lógica reconhecidamente neoliberal, que, no terreno da saúde pública, se coadunava com uma APS seletiva. Tal orientação governamental, no entanto, era contrabalançada pelo papel de uma militância pela reforma sanitária brasileira, neste período bastante organizada. Para estes, os princípios que se consagrariam na implantação do SUS, formalizados no texto das chamadas Leis Orgânicas da Saúde (LOS), só seriam garantidos

\footnotetext{
${ }^{2}$ Ao defenderem uma concepção de APS baseada na formulação de políticas e programas voltados para objetivos específicos e sempre relativos a grupos em situação de pobreza, os defensores de uma APS seletiva abririam uma frente de disputa com relação ao projeto desenhado em Alma-Ata, que considerava uma concepção de APS mais abrangente e estruturante para a organização dos sistemas de saúde. As tensões que envolveram tais disputas produziram consequências institucionais importantes no cenário específico brasileiro. Conforme argumenta Giovanella (2018:1), a adoção da expressão "atenção básica à saúde”, em contraposição ao uso internacionalmente consagrado de "atenção primária à saúde", no emprego corrente das lideranças do Movimento Sanitário Brasileiro, se relacionaria com uma diferenciação de natureza ideológica no que se refere ao reducionismo presente na proposta de uma Atenção Primária Seletiva. A rigor, as pretensões, os objetivos e o alcance imaginados para a reforma da saúde brasileira não seriam compatíveis com uma concepção seletiva de cesta restrita e focalizada das ações de saúde, concepção que, antes de tudo, não se alinhava à orientação do direito à saúde.
} 
por intermédio de uma série de políticas e investimentos públicos, inclusive com a vigência de uma APS abrangente (Aguiar, 2003; Lavras, 2011). Se vê, portanto, que o debate acerca da APS não se resumia aos enunciados favoráveis e restritivos à política. A questão que se colocava era de outra ordem: afinal, de que APS estamos falando?

Ainda que a criação do novo sistema tenha representado um avanço para o país e uma vitória do movimento pela Reforma Sanitária, o cenário nacional não apontava, necessariamente, para um caminho desprovido de contradições, de conflitos e de retrocessos. Fernando Collor de Mello (1990-1992), o primeiro Presidente eleito por voto direito na Nova República, vetou artigos importantes da LOS, em especial aqueles que versavam sobre descentralização, controle social e financiamento, ratificando o perfil de sua gestão que prezava por um Estado mínimo, e assim convergindo com a ideia de um sistema de saúde que se resumia a ações voltadas para os mais pobres. As formas de intervenção, por sua vez, se dariam por intermédio do uso de tecnologias de baixo custo, em boa medida alinhadas com a ideia do que se convencionou chamar de uma APS seletiva.

É verdade que ao longo dos anos seguintes uma série de portarias, projetos e programas vieram à público no âmbito do SUS afim de responder à algumas das expectativas construídas durante os processos de reforma sanitária e de democratização. Tais movimentos, contudo, apresentaram importantes oscilações, uma vez que, em certa medida, dependiam da orientação política das pessoas que ocupavam cargos de gestão na esfera federal, estadual e municipal, além da qualidade dos interesses dos diversos movimentos sociais e do setor privado. A metáfora que frequentemente dá conta desse processo é a do "copo meio vazio, meio cheio", em referência à manutenção de antigos problemas na Nova República, mas também de avanços e conquistas, ainda que parciais (RADIS, 2016).

Sem perder de vista estes marcos contextuais, o texto se encontra dividido em 4 partes. A primeira identifica os caminhos que levaram a consolidação do SUS, resgatando o papel central da Reforma Sanitária Brasileira nesse processo. A segunda retrata a história da criação do Programa de Agentes Comunitários de Saúde (PACS). A terceira aborda os desdobramentos do PACS, que ao longo dos anos foi aperfeiçoado, tornando-se o precursor do Programa Saúde da Família (PSF), criado em 1994. A quarta, e última parte, compreende a formulação e institucionalização da primeira Política Nacional de Atenção Básica (PNAB), com foco na identificação dos principais atores e mobilizações políticas necessárias para sua efetivação.

\section{A Reforma Sanitária, o SUS e a Atenção Primária à Saúde}


No início da década de 1980, a partir da derrocada da experiência de formulação do Programa Nacional de Serviços Básicos de Saúde (Prevsaúde), iniciativas de âmbito nacional estritamente voltadas para o arranjo de políticas no campo da APS pareciam entrar num ciclo de extinção. Tal imagem encontra respaldo no fato de não existir, ao longo da década, uma única iniciativa, mesmo que mera proposição, com robustez semelhante ao Prevsaúde.

É preciso, contudo, cautela antes que sejamos tentados a concluir a respeito de uma imaginada decadência no debate e na formulação de políticas de APS naquele período. O primeiro ponto que precisamos considerar é que o início da década coincide com os esforços mais sistemáticos, e também com implicações mais concretas para uma reorganização do sistema de saúde brasileiro. Nesse sentido, podemos dizer que nenhum outro tema, para além da instituição de um sistema único de saúde, se fez mais importante nas agendas dos atores setoriais naquele contexto. Tal afirmativa, contudo, não deve ser compreendida como a ascensão de uma agenda necessariamente antagônica à APS, uma vez que vários componentes dos debates relativos à formulação do SUS têm ampla ancoragem em experiências com a Atenção Primária, especialmente com aquela que se propunha "abrangente". São exemplos destas interfaces o debate e as iniciativas relativas à formulação de políticas no campo de recursos humanos ou a organização de regiões de saúde. Tal "simbiose" de agendas pode sugerir que, a rigor, a APS não tenha perdido necessariamente seu apelo e pertinência junto aos pensadores e gestores da saúde no contexto da reforma sanitária.

Outro ponto que merece atenção diz respeito aos empreendimentos de implantação da APS levados à cabo por prefeituras e/ou por estados federativos. Desta forma, ainda que se possa registrar a ausência de propostas de envergadura nacional na APS ao longo da década, não se pode dizer o mesmo com relação às iniciativas desenvolvidas em âmbito local. Tais experiências locais, mais adiante comentadas, não deixaram de se inscrever no processo de reforma nacional da saúde.

A este respeito é preciso ter em mente o que se convencionou chamar por Reforma Sanitária Brasileira. Uma primeira aproximação com relação à esta expressão revela a existência de um difuso movimento político e social, organizado em torno de profissionais de saúde, professores e discentes do campo que, em diálogo com as mais diversas instituições e movimentos sociais, militaram para o restabelecimento da democracia, concebendo, ao mesmo tempo, diferentes meios para viabilizá-la (Escorel, 1999; Gerschman, 2004; Escorel, Nascimento e Edler, 2005;). Quantos aos meios, pode-se simplesmente dizer que, pelo menos até certo ponto, os projetos concebidos por este movimento foram capazes de organizar distintas perspectivas, ambições e alcances sob uma mesma bandeira de luta. Se para uns a luta terminava 
com a conformação de aparatos político-institucionais capazes de viabilizar a participação social, bem como estabelecer meios concretos para a promoção, a prevenção e a reabilitação da saúde (Oliveira, 1988); para outros, a luta só alcançaria seus objetivos se a sociedade superasse o sistema capitalista e passasse a se organizar na forma socialista (Campos, 1988).

Sem a pretensão de esgotar as possibilidades de leitura de um fenômeno tão complexo, podemos concluir que as perspectivas mais referidas pela literatura remetem a existência de um amplo movimento social e político de vocação e alcance nacionais. No entanto, parte destes mesmos estudiosos reconhece que tal movimento de dimensões nacionais sempre contou, como substrato e expertise acumulada, com uma série de experiências locais (Teixeira, 1995). Nesse sentido, cabe pensar também a Reforma Sanitária Brasileira como um movimento cujo êxito político e institucional, em boa medida, é decorrente de sua capilaridade e capacidade de, sobretudo ancorado no movimento municipalista, se converter em iniciativas concretas levadas à cabo por governadores e prefeitos. Coube a estes últimos, no final das contas, a obrigação de ofertar políticas e serviços que serviriam como portas de entrada do recém implantado sistema de saúde (Campos, 1988; Fleury, 1997; Teixeira, 1988; Arouca, 1988; Oliveira, 1988).

A existência de uma série de experiências locais que tinham em vista a construção de redes de atenção em municípios e regiões, portanto, são partes essenciais do processo de construção do SUS. Afinal, após as chamadas LOS, era de se esperar que fossem pensadas estratégias operacionais, no mínimo retoricamente sintonizadas com as diretrizes e doutrinas do SUS. Tais políticas seriam construídas num vazio institucional? Nessa hora, o peso do passado se fez sentir e as tradições e aprendizados entorno de experiências locais deram o tom das ações. Era preciso, contudo, imprimir à estas diferentes experiências uma vocação que pudesse chamar nacional.

\section{Do Programa de Agentes Comunitários de Saúde (PACS) ao Programa de Saúde da Família (PSF)}

A partir da Conferência Internacional sobre Cuidados Primários de Saúde, realizada em Alma-Ata, no final da década de 1970, iniciou-se um consistente processo de disseminação de recomendações e orientações que fortaleciam propostas de ações de saúde em nível local, com foco na APS (OMS, 1978). No Brasil, experiências voltadas para atender demandas emergências em locais vulneráveis já estavam em curso, dentre elas a do Ceará, pioneiro na institucionalização do trabalho do Agente Comunitário de Saúde (ACS). A origem mais imediata do trabalho do ACS remete ao final dos anos 1970, quando os primórdios do que seria 
consolidado como o programa acontecia no município de Jucás no interior do estado. Essa experiência se expandiu no ano de 1987 por cerca de 14 municípios, compondo o Programa de Emergência, criado para atender as necessidades de famílias e crianças que se encontravam em situação de extrema vulnerabilidade em decorrência da seca (Marques Ávila, 2011).

Neste mesmo período, Tasso Jereissati, então governador do Estado do Ceará, se opunha a ideia de transferir recursos para que as pessoas em situação de pobreza sobrevivessem sem que ofertassem alguma contrapartida para o governo. A partir dessa premissa, o governo instituiu que seria preciso desenvolver alguma atividade para receber recursos estaduais, assim instituindo a contratação de seis mil mulheres do sertão cearense como agentes de saúde. Estas precisavam apenas ser pobres, em condições de trabalhar e conhecidas na comunidade em que desenvolveriam suas atividades (Marques Ávila, 2011; Lavor, 2018)

$\mathrm{O}$ resultado dessas medidas adotadas pelo governo se expressou especialmente no campo dos índices de saúde do segmento materno-infantil. Além disso, viabilizou a institucionalização de uma função no âmbito da saúde, o cargo de ACS, que anos mais tarde ganharia força e expandiria por todo o país ${ }^{3}$.

Em 1988, o Programa de Emergência chegou ao fim, todavia a melhora dos indicadores sociais, especialmente de saúde, ajudou a dar visibilidade ao trabalho das ACS, e demonstrou, em termos de políticas públicas, que aquela abordagem era capaz de produzir resultados consistentes. Nesse contexto, o governo cearense resolveu instituir o cargo de agentes de saúde por meio do Programa Agentes de Saúde (PAS), criado em janeiro de 1989, pioneiro no Brasil pelo caráter institucional e universalizado (Lavor, 2018).

Com a institucionalização, veio a expansão do programa e a contratação progressiva de pessoal com o intuito de garantir uma melhor cobertura dos serviços voltados para atender as necessidades básicas de saúde da população. Cabe destacar que as atribuições designadas para o cargo de ACS contribuíram para que a APS, aqui compreendida nos marcos dos "cuidados básicos de saúde", se difundisse pelo Estado do Ceará, resultando em uma mudança mais abrangente do perfil epidemiológico da região (Marques Ávila, 2011)

Em março de 1991, o PAS foi discutido como experiência modelar no âmbito do Ministério da Saúde. Estava em pauta a formulação e implementação, via Departamento de

\footnotetext{
${ }^{3}$ Cabe destacar que em outros momentos da história da saúde pública brasileira já existiu profissionais realizando a tarefa de visitar indivíduos e famílias em situação de vulnerabilidade para tratar questões de saúde. As visitadoras sanitárias, do início do século XX, constituem bom exemplo dessa longeva tradição. Elas foram enfermeiras que procuraram, por meio das visitas domiciliares, estabelecer vínculo direto com as famílias. Dessa forma, elas impulsionaram mudanças de comportamento a partir de práticas de educação sanitária e conhecimentos de higiene. (Fernandes et al, 2012)
} 
Operações da Fundação Nacional de Saúde (FUNASA), de um projeto de abrangência nacional. A experiência brasileira com a APS se modificaria com a criação do Programa de Agentes Comunitários de Saúde (PACS), como a principal estratégia do Ministério da Saúde para atender as demandas da população no nível primário. Com foco no grupo materno-infantil, tinha como objetivo anunciado expandir para outras regiões do país, a partir do Norte e Nordeste, daí se estabelecendo, gradualmente, uma ação no campo da atenção primária de corte nacional. (Marques Ávila, 2000; Souza, 2003).

Helvécio Bueno, diretor do Departamento de Operações da Funasa, indica que a proposta de trabalhar com ACS partiu da enfermeira sanitarista, e então presidente da FUNASA, Isabel Cristina Aparecida Stefano. O bastidor formal de criação do PACS se daria em uma reunião, realizada em 1991, entre Isabel e representantes da Unicef. A escolha de Helvécio, por seu turno, não teria sido por acaso, uma vez que este fora aluno de uma das figuras mais importante na implantação do ACS no estado do Ceará, o sanitarista Carlile Lavor (Sousa, 2003). O encontro, realizado em Taubaté-SP, definiu o comitê responsável por assessorar a equipe da FUNASA para elaboração do documento que instituiria o PACS como uma política nacional. No comitê contavam os coordenadores estaduais do Ceará, de Goiás, de Pernambuco e do Maranhão (Sousa, 2003). O projeto inicialmente apresentado contemplava três fases diferentes de implantação da política, ao final da última, o programa estaria vigente nas regiões de maior vulnerabilidade sanitária do país. Na primeira fase, definiu-se os estados do Nordeste como região prioritária, com exceção do Ceará, que já tinha, como vimos, seu próprio programa. A segunda fase seria a extensão do programa aos estados do Norte, principalmente Manaus e Belém. Já a terceira fase, prevista para execução a partir de meados de 1992, daria conta da implementação nos demais estados do Norte e nas periferias das principais capitais brasileiras.

Embora o planejamento tenha sido elaborado buscando sanar as urgências dos estados que apresentavam os maiores indicadores de mortalidade infantil, pobreza e demais carências, ele nunca chegou a ser cumprido, a última fase jamais aconteceu. Apenas em 1994, por intermédio do Programa de Saúde da Família (PSF), que o ACS, no modelo idealizado pelo PACS, chegou aos grandes centros urbanos e regiões metropolitanas. (Sousa, 2003)

Por se tratar de um projeto que implicaria mudanças na gestão da saúde dos estados, o processo de implementação da política não foi desprovido de tensões. Com o intuito de contemplar algumas das principais demandas suscitadas pelos gestores da saúde locais, no ano de 1991, o Ministério da Saúde organizou um encontro com o objetivo de discutir sua implementação. À mesa, lideranças da FUNASA, a coordenação nacional do PACS, os 
representantes da UNICEF, da Função da Oswaldo Cruz e da Pastoral da Criança, o Fórum Nacional de Entidade de Enfermagem e demais convidados. Os principais pontos de divergência se deram, principalmente, no que dizia respeito a instância que coordenaria a política e as atribuições dos agentes. Mas, sem qualquer dúvida, havia forte convergência de interesses e posições quanto a criação e fortalecimento de uma política que representasse maior protagonismo dos gestores municipais, foco nas comunidades e, é claro, utilização de ACS.

No final desse mesmo ano, um pouco mais de dois anos após a implantação do pioneiro Programa Agentes de Saúde no Ceará, Jarbas Vasconcelos, eleito prefeito de Recife, inicia a composição de sua equipe para a área da saúde. Uma das propostas iniciais envolvia justamente a implantação de um programa de agentes comunitários de saúde para o município. Em 1993, sob a condução de Guilherme Robalinho, secretário municipal de saúde, se institui a iniciativa na capital pernambucana. Entre suas propostas, tanto formar e qualificar ACS para atuação em regiões mais vulneráveis; quanto, por meio destes, desenvolver cuidados básicos de saúde com foco no indivíduo, na família e na comunidade para o enfrentamento da desnutrição, controle de doenças mais prevalentes, reidratação oral, controle de infecções respiratórias, acompanhamento do desenvolvimento infantil e controle de câncer (Prefeitura de Recife, 1993: p.11; Fernandes, 2014).

Segundo a então chefe da Divisão de Programa de Agentes Comunitários da secretaria municipal de saúde, Afra Suassuna Fernandes, a iniciativa tinha tanto inspiração na experiência cearense, quanto no modelo dos visitadores sanitários da Fundação Serviço Especial de Saúde, a FSESP, instituição recém extinta no país. Àquela altura, segundo Fernandes, o modelo sespiano seria readaptado e obedeceria à novas orientações. Em suas palavras:

O que a gente sabia de Fundação [SESP] é que era um modelo muito militarizado porque é tudo de cima para baixo e a ordem é essa. E a gente dizia "Não, não vai ser assim". Mas não era a discussão do que o visitador sanitário fazia ou deixava de fazer, porque era muito semelhante, a gente trabalhava com descrição de clientela, fazia o mapa, mas a base era sempre assim... Qual é a comunidade que quer? Onde a gente tem os piores indicadores? (Fernandes, 2014: p.14)

Ao mesmo tempo, em Niterói, região metropolitana da cidade do Rio de Janeiro, sob orientação doutrinária e técnica diversa, implantava-se a experiência do Médico de Família ${ }^{4}$. Suas raízes mais remotas estão também situadas no movimento municipalista e na ebulição do debate sobre saúde do contexto da década de 1980. Será, contudo, no início da década seguinte

\footnotetext{
${ }^{4}$ Para Hubner e Franco (2007:177), a Medicina de Família pode ser considerada como pertencente ao campo da Medicina Comunitária. No entanto, os autores consideram que a Medicina de Família traria uma peculiaridade: o foco da atenção na família e seu espaço singular, que é o domicílio.
} 
que localmente se reuniria as condições políticas que permitiram a adaptação da experiência cubana de medicina familiar (Teixeira et al, 1999).

O Programa Médico de Família veio à público em 1992. Ele era fruto da experiência de um grupo de técnicos que já tinha na bagagem a experiência do chamado Projeto Niterói, um empreendimento docente-assistencial desenvolvido pela Secretaria de Saúde na segunda metade da década de $1980^{5}$. Em 1989, uma coligação de partidos liderada pelo Partido Democrático Trabalhista (PDT) elegeu Jorge Roberto Silveira como prefeito da cidade (19891992). Silveira nomeou Gilson Cantarino O’Dwyer como Secretário Municipal de Saúde. Cantarino, como era conhecido, tinha sido justamente o Secretário Executivo do Projeto Niterói, estavam assim dadas as condições para manutenção das propostas de renovação do sistema local de saúde iniciadas anos antes. Em 1991, Cantarino realiza primeira visita à Cuba com o intuito de assinar os convênios de colaboração técnico-científica entre aquele país e a cidade Niterói. Um técnico designado pelo Ministério da Saúde de Cuba passou então a assessorar de forma permanente uma equipe multiprofissional designada pelo secretário para elaborar a proposta adaptada de saúde da família para o município (Souza, 2015:77).

Com foco nas regiões com piores condições de vida, com renda familiar mensal inferior a cinco salários mínimos, implantava-se, em setembro de 1992, o primeiro módulo do Programa Médico de Família (Teixeira, 1999; Souza, 2015). Em termos operacionais, o Programa era composto por uma equipe de coordenadores, supervisores, médicos e auxiliares de enfermagem. O módulo se organizava a partir da definição de microáreas. Cada setor, por sua vez, abrangia, em média, 1.200 pessoas. O território a que se vinculava o setor deveria permitir o acesso da equipe básica, médico e auxiliar, a todos os domicílios sem que se fizesse necessário o uso de meios de transporte (Hubner e Franco, 2007: 182-183).

O Programa mobilizava, portanto, noções e orientações técnico-doutrinárias caras à APS, como território de abrangência, equipe multiprofissional, vínculo comunitário, foco na família, entre outras. No entanto, a figura do ACS não estava presente na iniciativa de Niterói.

A inserção do conceito de ACS e deste ator no recém criado Sistema Único de Saúde constituiu um capítulo importante na gradual configuração de uma APS à brasileira, seja nas inúmeras experiências locais em configuração que mobilizaram esse ator, seja na conformação

\footnotetext{
${ }^{5}$ Segundo Souza (2015:73), por conta de uma epidemia de dengue no município de Niterói em 1986 e 1987 , a Secretaria Municipal de Saúde iniciou uma série de iniciativas e discussões com vistas a fortalecer o sistema local de saúde. Para tal, avançou-se na discussão sobre descentralização, reforma do currículo universitário e ampliação do campo de prática do hospital universitário. Esse conjunto de movimentos permitiu a formação de um grupo interinstitucional (UFF, INAMPS, SES e SMS), organizado em uma comissão executiva que passou a planejar um modelo de ações integradas pelas diferentes instituições públicas de saúde. Nasce assim o chamado Projeto Niterói.
} 
de uma matriz nacional para sua mobilização como trabalhador do SUS. Mais do que uma simples modalidade de trabalho e de trabalhador no sistema de saúde, a figura do ACS representava a definição de um modelo assistencial e assim implicava em uma necessária reordenação das práticas exercidas pelos diferentes profissionais já instalados no sistema de saúde.

Nesta perspectiva, em janeiro de 1994, o Ministério da Saúde publica o documento "Normas e Diretrizes" (Brasil/MS, 1994), texto em que a Gerência Nacional do PACS encaminha aos estados e municípios normas e diretrizes capazes de orientar e garantir o que seria uma uniformidade na implantação do Programa num país marcado por tantas diferenças sociais, econômicas e institucionais. Seu principal objetivo foi:

Incorporar ao Sistema Único de Saúde agentes comunitários de saúde, profissionalizados em auxiliares de enfermagem, para desenvolver ações básicas de saúde; identificar os fatores determinantes do processo saúde/doença; desencadear ações de promoção de saúde e prevenção de doença; funcionar como elo de ligação entre a população e os serviços de saúde, contribuindo, assim, com a comunidade no processo de aprender e ensinar a cuidar da sua própria saúde (Brasil/MS, 1994: p. 7).

Em termos organizacionais, o programa se estruturava a partir das ações de cinco esferas de operação: nacional, estadual, regional, municipal e local. Nacionalmente, previa uma Gerência Nacional, instalada na Coordenação de Saúde da Comunidade (Departamento de Operações da Funasa). A esta caberia funções de assessoria técnica na implantação do programa nos estados e municípios; desenvolver ações tendo em vista a formação de recursos humanos, especialmente de forma a garantir a profissionalização dos ACS como auxiliares de enfermagem, bem como a complementação da escolaridade de primeiro grau junto ao MEC nos casos necessários; garantir recursos financeiros para a manutenção das ações do programa; entre outras ações.

A política previa, ainda, a criação de uma coordenação estadual, cuja chefia seria indicada pelo secretário de estado de saúde. Entre suas funções, estabelecer critérios para a distribuição geográfica dos ACS, assessorar processos seletivos; acompanhamento e avaliação dos municípios, entre outras. Já o nível regional tinha entre suas responsabilidades assessoria técnica aos municípios, promover integração entre setores da educação regional e municipal; articular eventos intermunicipais, entre outros. Cabia às autoridades municipais apoiar toda a base operacional do processo de trabalho do ACS. Por fim, a esfera local, constituía-se como a operacionalização das atividades previstas pelo ACS. Este, morador há pelo menos dois anos na comunidade onde atuaria. Sob sua competência, o cadastramento de todas as famílias em 
sua área de abrangência, estímulo à organização comunitária, realização de ações básicas de saúde, tais como acompanhamento de gestantes, incentivo ao aleitamento materno, acompanhamento do desenvolvimento infantil de crianças de até 5 anos de idade, promoção da cobertura vacinal, controle de infecções respiratórias agudas e doenças diarreicas, orientação quanto às alternativas alimentares, medicina popular e promoção de ações de saneamento e melhoria do meio ambiente (Brasil/MS, 1994: p. 8-14)

Sua engenharia institucional, ao mesmo tempo, afinava-se e fortalecia orientações, princípios e diretrizes previstas nas LOS quanto ao funcionamento do SUS. Ao fim e ao cabo, este ganhava mais força muscular com a implantação de uma política nacional que, necessariamente, exigia articulação entre diferentes instâncias de poder e regiões do país. Aliás, o saldo positivo acerca da implantação do PACS é confirmado pela literatura especializada. Bornstein e Stoz (2008), por exemplo, sinalizam para o papel do ACS como elemento inovador no quadro funcional da APS e, ao mesmo tempo, como importante recurso para a mudança do modelo assistencial. Tal perspectiva é acompanhada por inúmeros outros estudos, inclusive e especialmente com foco em realidades específicas e locais, como é o caso de Saliba et al (2011). Mesmo autores com perspectivas mais críticas acerca do papel desempenhado pelos ACS, que apontam diversos problemas a ele associados, que vão da falta de condições de trabalho até desmotivação profissional, reconhecem ganhos nas atividades desempenhadas por este ator para o fortalecimento da APS e do SUS (Santos et al, 2011)

Segundo Vianna e Dal Poz (1998:17), o início do Programa da Saúde da Família se daria quando o Ministério da Saúde justamente formulou o PACS, pondo assim "a família como unidade de ação programática de saúde e não mais (tão-somente) o indivíduo, e foi introduzida a noção de área de cobertura (por família)". Em termos formais, a criação do PSF se contextualiza em uma reunião ocorrida em Brasília, em dezembro de 1993, sob o tema "Saúde da Família”. Por convocação do Gabinete do Ministro da Saúde Henrique Santillo, o encontro ocorria em resposta à uma série de demandas vindas dos secretários municipais de saúde. À mesa, técnicos do Ministério, secretários municipais de saúde, consultores internacionais e especialistas em APS, que discutiram a parcialidade da implantação do PACS, ainda restrito às regiões Norte e Nordeste, e demandavam a ampliação das ações de APS para todo o Brasil com uma necessária composição de ACS e outros profissionais de saúde (Vianna e Dal Poz, 1998: 19-20).

Como referem Vianna e Dal Poz (1998:20), o papel do Unicef teria sido muito importante em apoio às ideias e pautas dos secretários municipais de saúde. À época, o organismo contava com um técnico, Halim Antônio Girade, bastante identificado com as 
iniciativas em torno dos agentes comunitários. Outro parceiro, a Organização Pan-americana da Saúde estava mais empenhada no apoio à iniciativas no campo da organização dos sistemas locais de saúde (leia-se distritos sanitários), cujas interfaces com a APS eram reconhecidas, inclusive estavam estabelecidas em termos técnicos e doutrinários.

Nesse contexto, a reunião de dezembro comprometeu-se com a construção de uma nova política, capaz de incorporar outros profissionais e cobrir todo o território nacional. Como sinalizam Vianna e Dal Poz (1998: 20), a experiência exitosa de Niterói, relativa ao PMF, mobilizando médicos e profissionais da enfermagem, foi considerada um importante referencial para se pensar a composição de uma renovada política com base na atuação de equipes multiprofissionais de saúde.

Em setembro de 1994, por iniciativa do Ministério da Saúde, implantou-se o Programa de Saúde da Família. Apresentava-se como um instrumento do fortalecimento da APS, da municipalização e do SUS e, como vimos, tendo importante apoio dos secretários municipais de saúde. Seu processo de implantação se deu sob ritmo tal que em dezembro de 1999, cerca de cinco anos após sua implantação, atingia 1870 municípios nas então 27 unidades da federação. (Brasil/MS/CAB, 2000: p. 16)

Com intuito de compreender a situação de implantação do programa no país, em julho de 1999, o Ministério sistematizou uma "Pesquisa de avaliação da Implantação e Funcionamento do Programa de Saúde da Família". Seus resultados apontam, sem dúvida, para um processo de implantação vigoroso. Todas as secretarias estaduais de saúde do país, àquela altura, contavam com uma equipe técnica responsável pela coordenação local do PSF. Apenas em três estados federativos a coordenação do PACS e do PSF não se encontravam já unificadas (Brasil/MS/CAB, 2000: p. 16).

Algumas peculiaridades observadas no estudo conduzido pelo Ministério seriam, posteriormente, confirmadas em novos estudos e, ao que tudo indica, apresentam-se como características estruturantes no funcionamento do programa em nível nacional. Exemplo é a importante presença de enfermeiros na gestão do programa. No contexto do estudo, observouse que dos 24 estados com PSF implantado, apenas nove contavam com pelo menos um médico na equipe de coordenação. A presença de enfermeiros, ao contrário, era completa (Brasil/MS/CAB, 2000: p. 17). Outra questão observada, por assim dizer, crônica no funcionamento do programa, é a falta de apoio das autoridades sanitárias estaduais para o seu funcionamento. Registra-se, nessa linha, dificuldades e carências de toda ordem, equipamentos; reformas, ampliação e construção de unidades de saúde; carência de medicamentos; pagamentos de salários e repasse de recursos financeiros (Brasil/MS/CAB, 2000: p. 23). 
Em que pesem as dificuldades sinalizadas, a este estudo outros se juntam (Trad, Bastos, 1998; Macinko, Guanais FC, Souza, 2006; Facchini et al, 2006; Almeida, Giovanella, 2008), conferindo uma inegável robustez de resultados acerca da performance do Programa em termos nacionais e locais. Em termos acadêmicos, o PSF passou a se configurar, então, como um caso de sucesso na formulação e implementação de uma política de saúde.

No entanto, com a implantação e expansão do programa, antigos desafios intersetoriais, sobretudo na relação entre a saúde e educação, ganharam também um novo capítulo. A carência de profissionais de saúde, sobretudo de nível superior, somava-se a outro tradicional problema: a fixação de profissionais no interior e nas regiões menos abastadas, bem como a adequação qualitativa da formação profissional às necessidades do sistema de saúde (Gil, 2005; Cotta et al, 2006).

Em resposta a tais desafios, ao longo desse processo, registramos uma série de esforços no sentido de se construir uma política para a formação de recursos humanos afinada com as necessidades impostas pela APS e pelo SUS. Nos marcos desses esforços, destacamos o desenvolvimento, a partir de 1997, dos Pólos de Capacitação em Saúde da Família. Segundo Claudio Fonseca, então secretário de Políticas de Saúde do Ministério da Saúde, os Pólos teriam como principal objetivo "corrigir equívocos gerados na etapa de formação [profissional]" (Brasil/MS, 2002: 9). Para tal, a política visou a implantação de núcleos estratégicos em apoio aos profissionais do PSF, permitindo o desenvolvimento de habilidades de forma à capacitar profissionais para o que seria uma abordagem de atenção exercida de forma contínua, integral e coordenada.

A descentralização e a capacidade de implantação e condução de políticas de base municipal, sem dúvida, ganharam outro patamar a partir da implantação, em 1998, do Piso de Atenção Básica (PAB). Ele garantiu recursos federais para cada município brasileiro em função de um cálculo que considerou a sua população. Se, de um lado, representou a garantia de recursos financeiros; de outro, representou, também, responsabilidade por parte do gestor local na implantação de iniciativas no campo da Atenção Primária.

A prioridade dada à APS é, por si, um dado digno de nota. Mais do que uma prioridade formal, expressa nos discursos oficiais, o Ministério da Saúde tomou providências para que os recursos repassados, de fato, fossem empregados no desenvolvimento de ações compatíveis com o campo da APS. Para tal, no ano seguinte, expediu um Manual para a Organização da Atenção Básica (Brasil/MS, 1999). Um texto elaborado por núcleos técnicos do Ministério, mas que contou também com a colaboração do Conselho Nacional de Secretários de Saúde (CONASS) e do Conselho Nacional de Secretários Municipais de Saúde (CONASEMS). 
O Manual conceitua Atenção Básica, define responsabilidades dos municípios no que concerne a esta modalidade de atenção; elenca ações, atividades, resultados e impactos esperados das ações definidas; e, por fim, traz orientações quanto ao repasse dos recursos financeiros que compõem o PAB, bem como os mecanismos de acompanhamento e controle (Brasil/MS, 1999: p. 7). A rigor, dada sua robustez e detalhamento normativo, o Manual define, avant la lettre, uma política para Atenção Primária à Saúde no Brasil.

Os estudiosos que se debruçaram sobre este processo de fortalecimento da APS no país reconhecem a importância do PAB e das subsequentes orientações vindas do Ministério da Saúde, dos diferentes órgãos de assessoramento, de fóruns de discussão e deliberação técnica e política e também da academia como fundamentais para a inegável relevância política e conformação de consenso técnico acerca do papel da APS no processo de construção do SUS (Marques, Mendes, 2003; Souza et al, 2007).

A partir da segunda metade dos anos 1990, algumas coordenações estaduais do PACS e do PSF revelavam-se bastante atuantes no contexto da implantação e unificação das duas políticas em suas regiões. Pernambuco, Alagoas, Maranhão e Paraná, por exemplo, foram referidas como especialmente influentes naquele contexto, respectivamente sob a condução de Afra Suassuna Fernandes; Sônia Moura, Cristina Cordeiro Lopes e Armando Raggio (Fernandes, 2014). Na forma de consultorias ao Ministério da Saúde, apoiadas com recursos da Organização Pan-americana da Saúde (OPAS), estas e outras diferentes lideranças se juntaram aos técnicos já instalados no Ministério com vistas a avançar no processo de construção do necessário consenso técnico e político acerca da operação do programa em termos nacionais.

Em 2000, Afra Suassuna Fernandes é convidada para integrar, de forma permanente, a equipe técnica do recém criado Departamento de Atenção Básica no Ministério da Saúde, à época, sob a gestão do ministro José Serra. Sob a liderança de Heloisa Machado, na chefia do DAB, Afra assume a Coordenação da Expansão da Saúde da Família. A partir deste período, intensificando-se na gestão de Humberto Costa (2003-2005), seremos testemunhas não apenas de uma maior expansão do PSF no país, mas também de uma gradual reconfiguração da política.

Nessa época, a partir de algumas experiências municipais de ampliação das equipes de saúde da família, a iniciativa do Núcleo de Apoio à Saúde da Família, o NASF ${ }^{6}$, começou a ser

\footnotetext{
${ }^{6} \mathrm{O}$ NASF consiste em um aparato institucional com equipes multiprofissionais que atuam de forma integrada com as equipes de Saúde da Família. Tal atuação integrada permite, nos termos da política, realizar discussões de casos clínicos, atendimento compartilhado entre profissionais nas unidades de saúde e nos domicílios; e a construção conjunta de projetos terapêuticos. Essas ações de saúde também podem ser intersetoriais, com foco prioritário nas ações de prevenção e promoção da saúde (Brasil/MS, portaria 2488/2011)
} 
formulada. Somava-se também à ideia de melhor articular a APS aos demais níveis assistenciais. Segundo nos informa Afra Suassuna Fernandes:

Foi claramente em 2003, quando Humberto vem, aí já tinha alguma experiência também Antônio Mendes, com Humberto secretário e Antônio Mendes era Diretor de Atenção à Saúde, ele já pensava em algumas coisas. Adail Rollo de Campinas também já tinha algum embrião de alguma coisa. Tanto que Adail depois continuou, tanto que essa discussão de rede foi toda com ele. Mas a gente fez uma proposta sim, de rede com hospital secundário, a gente criou um incentivo, a gente começou a estudar. Aí 2003, 2004, 2005 (Fernandes, 2018: s/p).

A XII Conferência Nacional de Saúde, sob o tema "Saúde direito de todos e dever do Estado, o SUS que temos e o SUS que queremos", realizada em Brasília, em dezembro de 2003, ao contemplar o tema da inserção da Atenção Primária no SUS, revelava, tal como manifesto por Suassuna, uma crescente preocupação em conferir bases institucionais mais sólidas para a APS no país. Estruturada em 10 eixos temáticos, o da Organização da Atenção à Saúde abrigou discussões e orientações sobre “Atenção Básica e Saúde da Família”. Dois aspectos ganharam relevo neste tema: o primeiro foi a criação de incentivos técnicos financeiros, por parte das três esferas de governo, que garantissem a implantação da APS. O segundo envolveu a necessidade de organização e ampliação da APS, tendo a Saúde da Família como uma das portas de entrada e um programa rastreador de problemas de saúde da rede de serviços de saúde, e a partir da vigência de mecanismos de referência e contrarreferência (XII CNS, 2003: 80-81).

Ambientes acadêmicos, com vimos, mas também espaços ocupados por técnicos e gestores da saúde igualmente se lançavam em apoio à expansão da APS, sobretudo em sua modalidade saúde da família. Neste cenário, o processo de expansão e consolidação da APS/ESF no território nacional passou também a contar com recursos vultosos provenientes do Banco Mundial, que permitiram a construção do Projeto Expansão e Consolidação da Saúde da Família, o PROESF. A concepção do projeto se inicia, ainda, na gestão tucana de José Serra, mantendo-se como projeto prioritário na gestão petista de Humberto Costa. Seu propósito foi oferecer sustentabilidade aos municípios brasileiros com populações acima de 1 milhão de habitantes. A expansão em municípios pequenos e médios, até aquele momento, tinha se processado com relativo grau de sucesso, com o PROESF lançava-se um novo desafio: oferecer saúde da família à capitais e áreas metropolitanas.

Como parte do PROESF, a Avaliação para a Melhoria da Qualidade (AMQ), criada em 2005, instituiu uma metodologia de avaliação em diversos níveis: gestores, coordenadores, unidades de saúde e Equipes da Saúde da Família (EqSF), com o propósito de qualificação da Atenção Primária por meio de ações de avaliação (Morosini, Fonseca, Lima, 2018) 
No início das atividades do PROESF, foram selecionados quarenta municípios para o desenvolvimento de apoio e ações. Sua operacionalização contava com três componentes: o da expansão propriamente dita, a partir das cidades selecionadas; o de formação profissional, contando com estruturas e metodologias dos já referidos Polos de Capacitação em Saúde da Família; e, por fim, o componente de avaliação do projeto. A partir da gestão do Ministro Humberto Costa houve uma renegociação com o Banco Mundial e uma consequente ampliação do escopo de municípios contemplados. Das quarenta iniciais, o Projeto passou a contemplar mais de cem cidades.

À esta altura, os desafios em torno da implantação de um programa nacional, mas de base municipal, já estavam razoavelmente claros pelos seus gestores. Segundo Afra Fernandes Suassuna:

Vamos combinar que o Programa Saúde da Família no Nordeste tinha mais uniformidade. Quem vinha do Ceará, quem vinha de Pernambuco, então, tinha certo um alinhamento... Rogério de Sergipe, com Solla, a gente aqui em Pernambuco com Odorico no Ceará. (2018:s/p)

É interessante que o leitor perceba que as tensões que envolveram a nacionalização da política foram também atravessadas pelo debate acerca da descentralização e atribuições dos estados e municípios no âmbito da gestão da saúde sob os marcos institucionais do recém implantado SUS. Nesse sentido, conforme sinaliza Sousa (2003), cabe sinalizar que os técnicos das secretarias estaduais de Saúde, em alguns casos, reivindicaram a gestão direta do PACS. Para tal, se fundamentaram na proposta do SUS que prevê a esfera estadual como articuladora dos municípios. O SUS que permitiu o avanço da APS é o mesmo que, em algumas situações, dará sustentação legal aos conflitos no processo de expansão.

Infelizmente, em última análise, os conflitos não se resumiram às tensões relativas a um desejado processo de implantação do SUS. No que diz respeito às atribuições dos ACS, por exemplo, registramos desentendimentos também decorrentes das reivindicações de classe da Enfermagem que, alegando falta de clareza das responsabilidades dos agentes, percebeu-se ameaçada. A desqualificação da figura do ACS não deixou de resvalar, também, na própria Política, que tinha como uma de seus pilares o trabalho de base comunitária realizado pelos agentes. (Sousa, 2003).

Muitos outros desafios se acumulavam em decorrência da implantação de uma política que, como se vê, mexia com as bases do modelo de atenção à saúde brasileiro e, ao mesmo tempo, com práticas, identidades e territórios profissionais já razoavelmente calcificadas. 
Paradoxalmente, o PACS, mesmo que, em parte, estivesse inspirado em iniciativas do passado, colocava-se como uma ameaça às tradições.

\section{Conformação da primeira Política Nacional de Atenção Básica (PNAB)}

Com todas as dificuldades já até aqui consideradas, a partir de meados dos anos 2000 abriu-se uma fase promissora para a Atenção Primária à Saúde no Brasil. Amplia-se o consenso técnico e político acerca do papel da APS na organização das instituições e na reorganização do modelo de atenção à saúde. A sua contribuição para o processo de implementação institucional do SUS pode ser medida pela sua capacidade de "produzir saúde", entendida como um conjunto de ações com foco na cura e reabilitação da saúde, na prevenção e promoção de saúde e no acompanhamento de grupos considerados mais vulneráveis (Trad, Bastos, 1998; Macinko, Guanais FC, Souza, 2006; Facchini et al, 2006; Almeida, Giovanella, 2008)

Ao mesmo tempo, como parte do processo de institucionalização tanto da APS quanto do SUS, tais iniciativas ganhavam esteio institucional crescentemente mais sólido. A Fundação Nacional de Saúde (FUNASA), por exemplo, com base na Lei Orgânica da Saúde e, também, na Emenda Constitucional 29/2000, passou a exigir a obrigatoriedade de um Conselho Municipal de Saúde e a criação de um Fundo Municipal de Saúde, além da disponibilidade de profissional de saúde nível superior, no geral enfermeiro, para supervisionamento do trabalho dos ACS na Atenção Primária (Viana e Dal Poz, 1998).

A mesma Funasa ficou responsável também por todo o processo de descentralização de ações e serviços de saúde que teve início em 1993, com a transferências aos estados e municípios do gerenciamento e da execução de atividades até aquele momento exercidas pela Fundação Serviço Especial de Saúde Pública (Fsesp). Daí, na perspectiva de Viana e Dal Poz, (1998), o PACS/PSF ser compreendido como instrumento de reorganização dos modelos locais de saúde, não só pelos requisitos exigidos para a sua adesão, mas também porque viabilizou uma maior articulação entre estados e municípios.

Como parte das iniciativas de fortalecimento do SUS, no início de 2006, o Governo Federal publica o Pacto pela Vida. Tratava-se de um conjunto de compromissos sanitários, expressos em objetivos e resultados derivados da análise da situação de saúde do país, segundo prioridades definidas pelas diferentes esferas de governo. A iniciativa se organizava em seis frentes de atuação: Saúde do idoso; Câncer de colo de útero e de mama; Mortalidade infantil e materna; Doenças emergentes e endemias, com ênfase na dengue, hanseníase, tuberculose, 
malária e influenza; Promoção da saúde e, por fim, Atenção Básica à Saúde. Nesta última frente, pretendia-se "consolidar e qualificar a estratégia da Saúde da Família como modelo de atenção básica à saúde e como centro ordenador das redes de atenção à saúde do SUS" (Portaria 399, de 22/02/2006).

No final do mês seguinte, o Ministro Saraiva Felipe, por intermédio da Portaria 648/GM, instituía uma Política Nacional de Atenção Básica, estabelecendo, ainda, uma revisão de diretrizes e normas para a organização da Atenção Básica para os Programas Saúde da Família (PSF) e Agentes Comunitários de Saúde (PACS) (Brasil/MS, 2006b). A publicação da primeira $\mathrm{PNAB}$, no que se refere à dimensão mais conjuntural, se inseria completamente nas iniciativas e orientações do Pacto pela Vida. Além da centralidade da APS na organização do SUS, assumia-se que a Estratégia Saúde da Família seria um passo decisivo em um necessário processo de construção de uma APS forte, em tese, capaz de atender às necessidades de cobertura da população brasileira, prover cuidado de base integral e promoção da saúde, assim se configurando tanto como principal porta de entrada do cidadão no SUS quanto como eixo coordenador da Rede de Atenção à Saúde (RAS) (Morosini, Fonseca, Lima, 2018).

A política, portanto, chegava sem surpresas. Quando, por exemplo, a Secretaria de Atenção à Saúde do Ministério da Saúde, por meio do Departamento de Atenção Básica, apresentou na Comissão Intergestores Tripartite, o desenho de uma Política Nacional da Atenção Básica, que logo se implantaria, havia um contexto de acolhimento, de consenso técnico-político e de realizações que permitiam o recepcionamento de uma proposta que, a bem da verdade, era fruto e representava experiências e decisões que já se encontravam razoavelmente capilarizadas pelo país. Somava-se à esta trajetória, como dissemos, as orientações estabelecidas na conjuntura política, na forma dos princípios e diretrizes alinhavados no Pacto pela Vida, tal como definido em portaria de fevereiro de 2006 (Brasil/MS, 2006a).

A experiência acumulada nos diferentes níveis de gestão do SUS assim servia como estratégia complementar para facilitar a regulamentação da APS. As discussões para alcançar o formato final da PNAB, portanto, se alimentaram dos próprios eixos de organização do sistema de saúde brasileiro, em particular das ideias e orientações acerca da universalidade, da integralidade e da equidade. Os avanços se contextualizavam em um cenário de descentralização e de controle social do SUS, já consignados na legislação vigente. Assim, a nova política apontava para a redefinição dos "princípios gerais, responsabilidades de cada esfera de governo, infraestrutura e recursos necessários, características do processo de trabalho, 
atribuições dos profissionais, e as regras de financiamento, incluindo as especificidades da estratégia Saúde da Família".

Em que pesem as dificuldades registradas no caminho, na altura da primeira metade dos anos 2000, a agenda política de fortalecimento da APS por meio da ESF já se revelava visivelmente consolidada. O próprio conceito de Estratégia de Saúde da Família, entendido como um conjunto de ações de promoção da saúde, prevenção, recuperação, reabilitação de doenças e agravos mais frequentes nas famílias moradoras de um dado território, colocava-se praticamente como um consenso técnico por parte dos sanitaristas. Para tal, se concebeu a atuação de equipes multiprofissionais, formadas por médico, enfermeiro, auxiliares de enfermagem, agentes comunitários de saúde, cirurgião-dentista, auxiliar de consultório dentário ou técnico de higiene dental. A presente definição de equipe geraria importantes tensões com gestores municipais, que certamente se encontravam sob situações muito desiguais nas suas capacidades de implantar a política localmente. Diferentes realidades demográficas e epidemiológicas e a dificuldade de acesso à recursos, inclusive humanos, dão a medida da dificuldade do estabelecimento de uma política com padrões nacionais mais rígidos num país continental e repleto de desigualdades regionais. Não à toa, nos anos que seguem a implantação da PNAB, em 2011 e 2017, seremos testemunhas de processos de revisão técnica da política que, entre outras coisas, consideraram a flexibilização do conceito de equipe na ESF.

\section{Considerações finais}

Nos primeiros anos do século XXI, a APS ganhava o status de política nacional no Brasil. Nos termos da política implantada, tratava-se de uma iniciativa de reestruturação do modelo de atenção à saúde e de fortalecimento do sistema de saúde nacional. Mas, como vimos, os desafios e constrangimentos políticos e institucionais até que a área tivesse acesso a este lugar no podium não foram pequenos. Seu processo de construção se processou em um contexto em que figuravam imensas incertezas políticas e institucionais.

Em primeiro lugar, não estava dado que o país conseguiria superar com relativo êxito o regime autoritário há cerca de duas décadas no comando das instituições e da vida política. $\mathrm{O}$ processo de abertura, em boa medida exitoso, envolveu muitos atores, instituições, áreas de conhecimento e estratégias políticas, uma amplidão de iniciativas que foge aos objetivos do nosso texto. A área de saúde, contudo, teria seu quinhão nesse empreendimento desafiador.

Os esforços e políticas com vistas ao estabelecimento de uma democracia de fato, mediante o estabelecimento de políticas sociais capazes de garantir direitos de cidadania, foram 
a peça-chave de um amplo e difuso movimento da saúde, conhecido como "sanitário". Na alvorada desse movimento, em finais dos anos 1970, a APS se apresentou, por assim dizer, de forma um tanto vigorosa na agenda setorial. Com o nome Programa Nacional de Serviços Básicos de Saúde (Prevsaúde), algumas lideranças do setor tentaram emplacar aquela que seria a primeira política nacional para APS do país. As forças políticas contrárias ao movimento, contudo, prevaleceram diante do desejo de mudança.

Na década seguinte, no entanto, sempre sob imenso constrangimento político, amplas mudanças se estabeleceram na sociedade brasileira. A promulgação de um nova Constituição, em que se instituía a saúde como um direito de cidadania, representou tanto uma base jurídica sólida para o vivo desejo de mudança como também apontava para uma necessária agenda de realizações práticas que fossem capazes de institui-la no terreno da vida concreta das pessoas.

É justo neste contexto de vigência de potentes marcos legais e de implantação de um Sistema Único de Saúde que a APS se apresentará como uma das estratégias de conversão de desejos em realidade. A partir daí, em uma trajetória de cerca de 30 anos, fomos testemunhas da multiplicação e consolidação da formação de atores com identidade com a área, ao mesmo tempo em que vimos eclodir uma série de empreendimentos e iniciativas locais de organização dos serviços de saúde que, no mínimo, conversavam com as ideias postas em Alma-Ata.

De um lado, por conta das longevas práticas e tradições da saúde pública brasileira; de outro, por conta de um vigoroso e progressista debate sobre saúde capitaneado por um "movimento sanitário", o país se converteria em um dos palcos de uma disputa internacional acerca do significado e do alcance da APS. Num movimento que, nos parece, combinou, em certo sentido, virtuosamente aspectos históricos e conjunturais, a defesa de uma APS abrangente foi se definindo como um ponto de chegada para a oferta de políticas de APS no Brasil.

Em linhas muito gerais, compreendemos que a formulação e implementação, a partir de 2006, da primeira Política Nacional de Atenção Básica (PNAB) é parte inseparável de um processo que, de um lado, envolveu a garantia do direito à saúde; de outro, envolveu a oferta de uma APS abrangente com vistas à mudanças do modelo assistencial à saúde vigente no país.

Para tal, foram mobilizadas instituições, atores e aprendizados adquiridos localmente ao longo do tempo. Como os atores desse processo costumam referir, à golpe de portarias, projetos e programas foram se construindo às condições que definiriam experiência da APS no Brasil. Não se trata de um movimento linear, oscilações se contextualizavam nas diferentes orientações políticas das pessoas que ocupavam cargos de gestão na esfera federal, estadual e municipal, além da qualidade dos interesses dos diversos atores envolvidos. Como comentamos na abertura 
do texto, trata-se do "copo meio vazio, meio cheio", em referência aos avanços e conquistas que se apresentam quase sempre como parciais (RADIS, 2016).

É nesse sentido que consideramos a PNAB como parte de um longo processo cumulativo de doutrinas e perspectivas organizacionais e de exercício do cuidado profissional para a saúde no Brasil. A PNAB é, por assim dizer, histórica. Mas não é, por outro lado, mera continuidade e vínculo com o passado. Ela é igualmente parte dos esforços de uma renovada geração de sanitaristas, trabalhadores e cidadãos na luta pela saúde que, em seu tempo, souberam inscrever no interior do Estado brasileiro a perspectiva de uma "tradição renovada".

\section{Referências bibliográficas}

ÁVILA, Maria Marlene Marques. O Programa de Agentes Comunitários de Saúde no Ceará: o caso de Uruburetama. Ciência \& Saúde Coletiva, v. 16, p. 349-360, 2011.

ÁVILA, Maria Marlene Marques. Origem e evolução do programa de Agentes Comunitários de Saúde no Ceará. Revista Brasileira em Promoção da Saúde, v. 24, n. 2, p. 159-168, 2012. AGUIAR, Raphael Augusto Teixeira. A construção internacional do conceito de atenção primária à saúde (APS) e sua influência na emergência e consolidação do sistema único de saúde no Brasil. [Dissertação de Mestrado]. Belo Horizonte: Faculdade de Medicina, Universidade Federal de Minas Gerais; 2003.

ALMEIDA, Patty Fidelis de; GIOVANELLA, Ligia. Avaliação em Atenção Básica à Saúde no Brasil: mapeamento e análise das pesquisas realizadas e/ou financiadas pelo Ministério da Saúde entre os anos de 2000 e 2006. Cad. Saúde Pública [online]. 2008, vol.24, n.8, pp.17271742

BORGES, Camila Furlanetti; DE FARIAS BAPTISTA, Tatiana Wargas. A política de atenção básica do Ministério da Saúde: refletindo sobre a definição de prioridades. Trabalho, educação e saúde, v. 8, n. 1, p. 27-53, 2010.

BORNSTEIN, Vera Joana; STOTZ, Eduardo Navarro. O Trabalho dos agentes comunitários de saúde: entre a mediação convencedora e a transformadora. Trab. educ. saúde [online]. 2008, vol.6, n.3, pp.457-480.

BRAGA, Ialê Falleiros; MELO, M. P. Reforma da aparelhagem estatal: novas estratégias de legitimação social. In: Lúcia Maria Wanderley Neves. (Org.). A nova pedagogia da hegemonia: estratégias do capital para educar o consenso. 1ed.São Paulo: Xamã, 2005, v. 1, p. 175-192.

Brasil/MS. Reunião dos coordenadores dos Pólos de capacitação, formação e educação permanente em saúde da família. Relatório Final. Brasília, DF: Secretaria de Políticas de Saúde/Departamento de Atenção Básica, 2002.

Brasil/MS. PORTARIA No 2488, DE 21 DE OUTUBRO DE 2011. Aprova a Política Nacional de Atenção Básica, estabelecendo a revisão de diretrizes e normas para a organização da Atenção Básica, para a Estratégia Saúde da Família (ESF) e o Programa de Agentes Comunitários de Saúde (PACS).

Brasil/MS. PORTARIA No 399, DE 22 DE FEVEREIRO DE 2006. Divulga o Pacto pela Saúde 2006a - Consolidação do SUS e aprova as Diretrizes Operacionais do Referido Pacto. BRASIL/MS. Política Nacional de atenção básica / Ministério da Saúde, Secretaria de Atenção à Saúde, Departamento de Atenção à Saúde. - Brasília : Ministério da Saúde, 2006b. 
BRASIL/MS. Manual para a organização da Atenção Básica. Brasília-DF: Ministério da Saúde, 1999.

BRASIL/MS. Normas e Diretrizes. Brasília, DF: Ministério da Saúde, 1994.

BRASIL/MS/CAB. Avaliação da implantação e funcionamento do Programa de Saúde da Família - PSF. Brasília-DF: Ministério da Saúde/Secretaria de Assistência à Saúde/Coordenação de Atenção Básica, 2000.

CAMPOS, Gastão Wagner de Sousa. A reforma sanitária necessária. In: Berlinguer, Giovanni; Teixeira, Sonia Fleury; Campos, Gastão Wagner de Sousa. Reforma sanitária: Itália e Brasil. São Paulo: Editora Cebes; Hucitec. p.179-194. 1988.

COTTA, Rosângela Minardi Mitre et al. Work organization and professional profile of the Family Health Program: a challenge in the health basic attention restructuring[ign]. Epidemiol. Serv. Saúde [online]. 2006, vol.15, n.3

DECLARAÇÃO, DE ALMA-ATA. Conferência Internacional sobre cuidados primários de saúde. Alma-ata, URSS, v. 6, 1978.

ESCOREL, Sarah. Reviravolta na saúde: origem e articulação do movimento sanitário. Rio de Janeiro: Editora Fiocruz, 1999.

ESCOREL, Sarah; NASCIMENTO, Dilene R.; EDLER, Flavio. As origens da reforma sanitária e do SUS. In: Lima, Nísia Trindade et al. (Org.). Saúde e democracia: história e perspectivas do SUS. Rio de Janeiro: Editora Fiocruz. p.59-81. 2005.

FACCHINI, Luiz Augusto et al. Desempenho do PSF no Sul e no Nordeste do Brasil: avaliação institucional e epidemiológica da Atenção Básica à Saúde. Ciênc. saúde coletiva [online]. 2006, vol.11, n.3.

FAUSTO, Márcia Cristina Rodrigues; MATTA, Gustavo Corrêa. Atenção Primária à Saúde: histórico e perspectivas. Morosini MVGC, organizador. Modelos de atenção e a Saúde da Família. Rio de Janeiro: EPSJV/Fiocruz, 2007: p. 43-67.

FERNANDES ARIAL AYRES, Lílian et al. As estratégias de luta simbólica para a formação da enfermeira visitadora no início do século XX. História, Ciências, Saúde-Manguinhos, v. 19, n. 3, 2012.

FERNANDES, Afra Suassuna. Entrevista concedida a Carlos Henrique Paiva e Fernando A. Pires-Alves, Recife, outubro de 2018. Disponível em: http://observatoriohistoria.coc.fiocruz.br/php/level.php?lang=pt\&component=44\&item=5

GERSCHMAN, Silvia. A democracia inconclusa: um estudo da reforma sanitária brasileira. Rio de Janeiro: Editora Fiocruz. 2004.

GIL, Célia Regina Rodrigues. Formação de recursos humanos em saúde da família: paradoxos e perspectivas. Cad. Saúde Pública [online]. 2005, vol.21, n.2 [cited 2020-07-06], pp.490-498. GIOVANELLA, Ligia; MENDONÇA, Maria Helena. "Atenção Primária à Saúde”. In: Ligia Giovanella et al (Orgs). Políticas e sistema de saúde no Brasil. Rio de Janeiro: Ed. Fiocruz, 2012: 493-546.

HUBNER, Luiz Carlos Moreira; FRANCO, Túlio Batista. O programa médico de família de Niterói como estratégia de implementação de um modelo de atenção que contemple os princípios e diretrizes do SUS. Physis [online]. 2007, vol.17, n.1.

LAVRAS, Carmen. Atenção primária à saúde e a organização de redes regionais de atenção à saúde no Brasil. Saude soc. [online]. 2011, vol.20, n.4

MACINKO J, Guanais FC; SOUZA, Fátima Marinho de. MEvaluation of the impact of the Family Health Program on infant mortality in Brazil, 1990-2002. Journal of Epidemiology \& Community Health;60, 2006:p. 13-19.

MARQUES, Rosa Maria and MENDES, Áquilas. Atenção Básica e Programa de Saúde da Família (PSF): novos rumos para a política de saúde e seu financiamento? Ciênc. Saúde Coletiva [online]. 2003, vol.8, n.2. 
MOROSINI, Márcia valeria Guimarães; FONSECA, Angélica Ferreira; LIMA, Lucina Dias de. Política Nacional de Atenção Básica 2017: retrocessos e riscos para o Sistema Único de Saúde. Saúde debate 42 (116) Jan-Mar 2018.

MELLO, Guilherme Arantes. Revisão do pensamento sanitário como foco no Centro de Saúde. Tese de doutorado defendida na Faculdade de Medicina da USP. São Paulo, 2010

MENDES, Eugênio Vilaça. Distritos Sanitários: a mudança das práticas sanitárias no SUS.. São Paulo: Ed. Hucitec, 1993. Distrito sanitário: o processo social de mudança das práticas sanitárias do Sistema Único de Saúde. São Paulo, Ed. Hucitec, $3^{\text {a }}$ ed., 1995.

OLIVEIRA, Jaime A. Reformas e reformismo: "democracia progressiva” e políticas sociais (ou "para uma teoria política da reforma sanitária"). Cadernos de Saúde Pública, Rio de Janeiro, v.3, n.4, p.360-387. 1988.

PREFEITURA DE RECIFE. Programa de Agentes Comunitários de Saúde. Recife, PE: Prefeitura da cidade de Recife, 1993.

RAD, Leny Alves Bonfim and BASTOS, Ana Cecília de Sousa. O impacto sócio-cultural do Programa de Saúde da Família (PSF): uma proposta de avaliação. Cad. Saúde Pública [online]. 1998, vol.14, n.2.

RADIS. Revista Radis. Vol. 169. Rio de Janeiro: Fiocruz, 2016.

SALIBA, Nemre Adas; GARBIN, Cléa Adas Saliba; SILVA, Fabíola Sira Jorqueira Ferro Bueno; PRADO, Rosana Leal do. Agente comunitário de saúde: perfil e protagonismo na consolidação da atenção primária à saúde. Cad. Saúde Colet., 2011, Rio de Janeiro, 19 (3): 318-26

SANTOS, Karina Tonini dos et al. Agente comunitário de saúde: perfil adequado a realidade do Programa Saúde da Família?. Ciênc. Saúde Coletiva [online]. 2011, vol.16, suppl.1 [cited 2020-07-01], pp.1023-1028.

SOUZA, Camille Melo Barreto. A trajetória de implementação do Programa Médico de Família em Niterói: continuidades e mudanças nos anos 2000. (Dissertação de mestrado), 2015.

SOUSA, Maria de Fátima de. Agentes comunitários de saúde: choque de povo. In: Agentes comunitários de saúde: choque de povo. 2003.

SOUZA, Maria De Fátima Marinho De; MACINKO, James, Alencar, Airlane Pereira; MALTA, Deborah Carvalho; MORAIS NETO, Otaliba Libânio De. Reductions In FirearmRelated Mortality And Hospitalizations In Brazil After Gun Control. HEALTH AFFAIRS. VOL. 26, NO. 2, março de 2007: 575-584.

TEIXEIRA, Sonia Fleury. Projeto Montes Claros: a utopia revisitada. Rio de Janeiro: Abrasco, 1995.

TEIXEIRA, Suely C. S.; MONTEIRO, Valéria de O. and MIRANDA, Verônica A.. Programa médico de família no município de Niterói. Estud. av. [online]. 1999, vol.13, n.35

VIANA, Ana Luiza; DAL POZ, Mario Roberto. A reforma do sistema de saúde no Brasil e o Programa de Saúde da Família. Physis: Revista de Saúde Coletiva, v. 8, p. 11-48, 1998. 